\title{
Not in my hiking trail? Acceptance of wind farms in the Austrian Alps
}

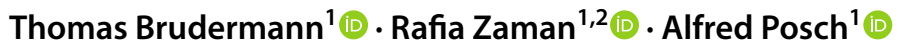

Received: 17 January 2019 / Accepted: 19 July 2019 / Published online: 29 July 2019

(c) The Author(s) 2019

\begin{abstract}
Large-scale wind power projects are one of the bearers of hope for a transition toward low-carbon electricity systems. The question of social acceptance of such projects near residential areas, or acceptance of the technology in general, has received significant attention in the scientific literature. Less attention has been placed on acceptability of wind farms in sparsely inhabited mountain areas; the focus of this paper therefore is on acceptance of wind farms in the Austrian Alps from the perspective of tourists and day trippers. We conducted a quantitative survey with visitors of alpine regions $(n=137)$ in proximity to recently constructed wind farms and identified drivers of (non-)acceptance by means of bivariate correlations and multiple linear regressions. Results indicate a high acceptance of wind technology in general and fairly high acceptance for the existing projects. Acceptance levels, however, are slightly, but significantly lower when respondents were asked to rate acceptability of wind farms in the Alps in general. Perceived benefits and reliability of wind power is the strongest predictor variable for higher acceptance levels, while annoyance through visual impact and noise is the strongest predictor variable for lower acceptance levels. Interestingly, factors like degree of information, concern regarding environmental impacts, trust in decision makers and climate change concern do not significantly affect acceptance levels. At the moment, no major opposition to wind power can be identified among tourists. Policy makers therefore should emphasize benefits of wind farms, as respective perceptions are a main predictor for acceptance. Operators should take annoyance concerns seriously, as this factor is predominant in predicting non-acceptance.
\end{abstract}

\section{Graphic abstract}

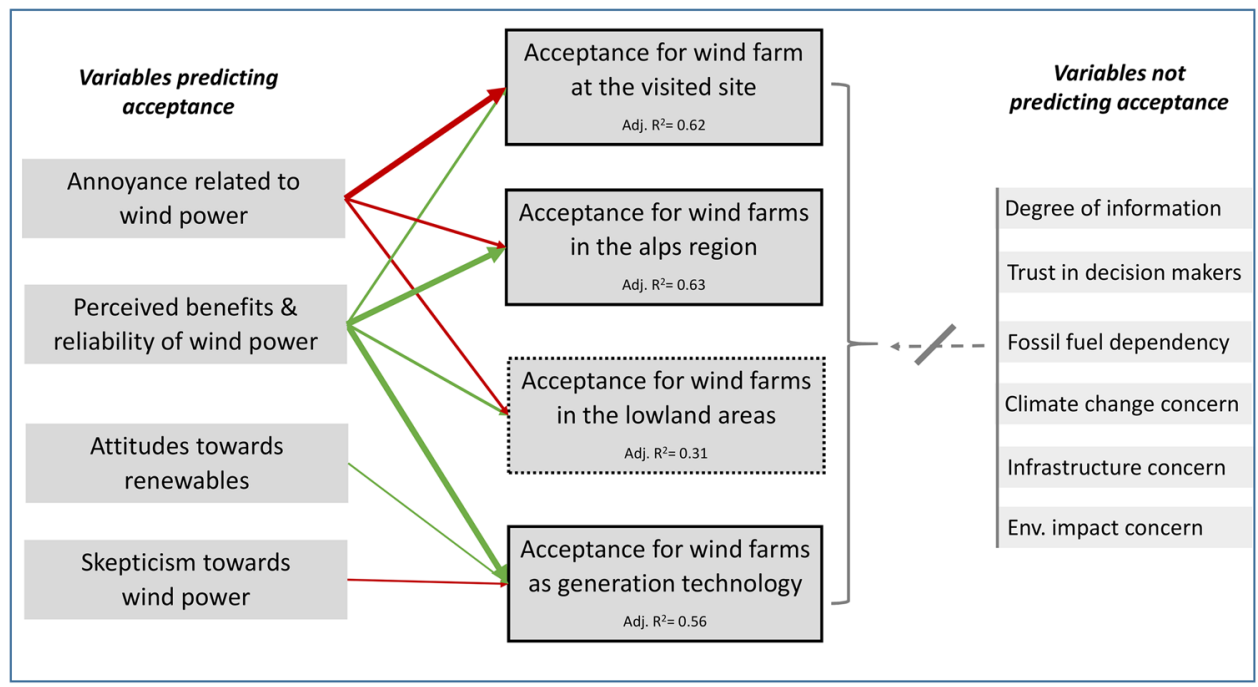

Electronic supplementary material The online version of this article (https://doi.org/10.1007/s10098-019-01734-9) contains supplementary material, which is available to authorized users.

Extended author information available on the last page of the article 
Keywords Wind energy $\cdot$ Public acceptance $\cdot$ Tourists' acceptance $\cdot$ NIMBY $\cdot$ Energy tourism $\cdot$ Energy policy

\section{Introduction}

Global emission reduction targets require a decarbonization of electricity systems. Clean energy technologies such as wind power and solar photovoltaics (PV) have become technically and economically viable following technological advancements and declining generation costs (Duić 2015). Globally, power plant investment is already dominated by renewables: Wind and PV together make up for almost 45\% of investments according to the World Energy Outlook (IEA 2017, p. 251). Consequentially, large-scale wind power projects are, besides a massive scale-up of PV, one of the bearers of hope for a transition toward low-carbon electricity systems.

Large-scale energy projects, however, often spark controversies in the public, and wind farms (or wind parks), i.e., projects involving a number of wind turbines on the same site, are no exception. Apart from technical challenges (wind forecasting, structural challenges, reliability, system integration), social acceptance of (large and noisy) wind turbines presents a key challenge (McKenna et al. 2016). A large body of the literature has addressed the question of social acceptance of both small- and large-scale wind power projects. It was found that the public well accepts wind power in general, and that various factors influence the degree of acceptance.

\section{Theoretical background: public acceptance of wind power}

Acceptance studies for wind power projects have been conducted on numerous occasions, and in several countries. The focus in the majority of cases was placed on local acceptance by residents or on public acceptance by the general population, as the following examples illustrate: A recent review paper (Rand and Hoen 2017) reported that support for wind power in North America was consistently high over the last 30 years. A representative German study (Sonnberger and Ruddat 2017) found good acceptance levels for offshore wind farms and slightly lower acceptance levels for onshore wind farms; wind farms in close proximity to one's residence, however, were found not acceptable or rather not acceptable by $45 \%$ of respondents. Walter (2014) in a study with 919 Swiss citizens of rural municipalities with potential wind sites found rather high acceptance levels for local wind energy projects and positive attitudes toward wind energy in general. A study from Cyprus reported positive public opinion on a large-scale wind farm project with a majority of respondents considering the project acceptable and as of no considerable environmental impact (Fokaides et al. 2014). Also a Chinese study (Yuan et al. 2015) found rather high acceptance levels of wind farms, but also noted that these can easily be undermined by improper procedures or lack of transparency. Another Chinese study (Guo et al. 2015) reported that the acceptance rates were lowest when the source of wind power was located in their village or neighborhood, but highest when in the same county or city. Japanese residents living in vicinity of a site strongly (38\%) or somewhat $(49 \%)$ approved the existing project, while only $3 \%$ strongly disapproved; approval and disapproval of a hypothetical additional project was balanced among the same residents (Motosu and Maruyama 2016).

In Austria, acceptance of renewable energies is being surveyed on an annual basis with representative samples. The results of the latest study are in line with the internationally reported good acceptance of wind energy, and $72 \%$ of Austrians approve of the technology (University of Klagenfurt, WU Vienna University of Economics and Business, Deloitte Austria, \& Wien Energie 2018). Interestingly, the highest approval rates can be found in regions with a high number of wind energy projects, i.e., in the federal states of Burgenland (88\%) and Lower Austria (78\%), which together make up for more than $90 \%$ of the present national generation capacity.

In general, acceptability of wind farms is good, but the location of the wind farm influences acceptance rates. Nonetheless, location is only one of the factors explaining acceptance or resistance to wind farms: The NIMBY ("not in my backyard") phenomenon has long been used as the prime explanation for the discrepancy between acceptance for the technology and resistance to concrete projects, but is increasingly being criticized in academic literature. Rand and Hoen (2017) criticize the NIMBY framework as too simplistic and unable to explain the complex process leading to negative attitudes; in a similar vein Sposato and Hampl (2018) see limited value in the NIMBY framework. NIMBY resistance might rather be a result of negative attitudes, but not an explanation for them (Rand and Hoen 2017). Accordingly, results from a Czech study suggest that perceived landscape disruption is significantly affected by perceived economic benefits to local communities, perceived negative impacts such as noise and respondents' level of education, while the number of wind turbines and proximity to residences do not predict perception of landscape disruption (Frantal et al. 2017).

Apart from wind farm location, several other factors may determine individual acceptance levels and have been reported in the literature accordingly.

One factor is the attitude toward renewable energy and energy transition in general (Sonnberger and Ruddat 2017). 
A positive attitude toward renewable energy usually predicts high acceptance levels, while technology skepticism and belief on fossil fuel reliance reduce acceptance levels (Sposato and Hampl 2018). Attitude toward climate change and climate change concerns are often related to renewable energy acceptance (Guo et al. 2015; Tatchley et al. 2016). The general attitude toward wind power as a generation source furthermore was found to be a strong predictor for the acceptance of concrete projects (Walter 2014). Related to that the perceived degree of information or knowledge regarding advantages and disadvantages of wind energy and renewable energies is likely to influence renewable energy attitudes.

Wind farms come with certain benefits; various economic benefits such as a potentially positive impact on job markets complement the potential social and environmental benefits such as safety, reliability or low emissions during the operation phase. Perceived benefits positively affect acceptance rates. On the other hand, concerns regarding environmental impacts are predictors for low acceptance; these include danger for birds and bats (Sonnberger and Ruddat 2017), negative effects on wildlife (Groth and Vogt 2014; Scherhaufer et al. 2017) and negative effects of the construction on the local environment (land use, use of concrete and steel, road infrastructure and transmission lines). Based on their review of North American studies, Rand and Hoen (2017) assume that environmental concerns do matter, but perhaps less than other factors.

Apart from direct negative effects on human ecology (Scherhaufer et al. 2017) people might simply be annoyed by a wind farm that spoils the landscape character, causes visual intrusions (D'Souza and Yiridoe 2014), reduces the quality of the recreational area (Broekel and Alfken 2015; Frantál and Kunc 2011) and on top of that generates unpleasant noise. Rand and Hoen (2017) found in their review that sound and visual impacts strongly tie to annoyance and in further consequence opposition. On the other hand, residents find wind turbines in motion-which obviously are more noisy-more beautiful than static turbines (Fergen and Jacquet 2016).

Moreover, it also matters how the decision for a wind power project is being made, and who is included in the process. A planning process which is perceived as fair can lead to greater toleration of the outcome, even if it does not fully satisfy all stakeholders (Rand and Hoen 2017). It was argued that advantages and disadvantages of a wind farm should be fairly distributed among stakeholders and also include ordinary citizens (Sonnberger and Ruddat 2017), involving participatory, procedural and distributional justice (Hall et al. 2013; Liebe et al. 2017). Warren and McFadyen (2010) reported that compared to privately owned wind farms, community ownership increases social acceptance of wind farms. Trust in decision makers and key stakeholders (local municipalities, regional decision makers, governments, energy companies) plays a role here as well (Hall et al. 2013).

Demographic variables such as gender, income and education level seem to have little explanatory power for variation in wind energy support or attitudes according to Rand and Hoen (2017); Frantal et al. (2017) partly disagree and see the education level as a relevant factor; Betakova et al. (2016), moreover, found differences in perceptions of wind turbines depending on study backgrounds of respondents. This inconsistency, however, might also be attributed to cultural/national differences between the reported cases in Northern America and the Czech Republic.

\section{Wind farm acceptance by tourists}

While studies on public and local acceptance of wind power have been conducted on numerous occasions, acceptance by tourists or day trippers is relatively understudied. Negative impacts on tourism are frequently mentioned as concerns by locals, but studies directly involving tourists are rare. Also, studies on tourist perceptions rarely deal with wind farms in mountain regions, but rather with projects in the countryside or in offshore locations.

The quantitative study by Sæpórsdóttir et al. (2018) on a proposed project in the southern Highlands of Iceland is one of few exceptions. A majority of surveyed tourists in their study stated that the wind farm would decrease the area's attractiveness, but only one-third stated that a visit would be less likely in case the project was implemented. $60 \%$ of respondents in this study claimed that a wind farm would not affect their decision to visit the area. In line with insights from studies involving the general public, results furthermore indicated that tourists visiting Icelandic Highlands were in general positive toward renewable energy, with a less positive attitude toward wind than to other technologies. Landscape disruption was one main negative factor associated with the project.

Two qualitative case studies in the Portuguese countryside came up with similar conclusions. Although most visitors disliked the proximity of turbines to medieval architecture in a cultural heritage site, their presence was largely accepted, and not seen as a factor in the choice of destination (Silva and Delicado 2017). Visitors of another historical village did not report any significant impact of the wind farm on their tourist experience and sometimes even highlighted the positive aspects (de Sousa and Kastenholz 2015).

Apart from wind farms in popular mountain or countryside areas, wind farms close to tourist beaches are of concern as well. A handful of studies dealt with tourists' acceptance of offshore wind farms in the Mediterranean region: Choice experiments conducted with tourists at French beaches (Westerberg et al. 2015) suggested that factors like visibility, 
opinion on climate change, efficiency of the technology and attitudes toward renewables influenced perceived impacts of the wind farm on the holiday experience. Voltaire et al. (2017) in a Catalan case study speculated that the construction of wind farms could cause a shift in trips to beaches without wind farms in their vicinity. This study, however, was based on self-reported intentions regarding future trips in hypothetical cases of wind farm construction. Work by Frantál and Kunc (2011) on Czech case areas indicated that the construction of wind turbines has only negligible negative impact on tourists perception and destination choice, if the turbines are constructed in suitably selected locations. In general, it can be said that there is little evidence of wind farm constructions negatively affecting tourism, and occasionally positive effects have been reported as well (Westerberg et al. 2013). Nonetheless, the necessary transmission lines might very well disturb tourists (Stefánsson et al. 2017) as well as locals.

With regards to potential positive impacts, energy tourism is emerging as a new niche of industrial tourism, and wind farms are being increasingly utilized to attract tourists (Frantál and Urbánková 2017; Liu et al. 2016). Obviously, there may be potential negative, but also potential positive impacts of wind farms on tourism in the affected region.

\section{Research gap and aim of the paper}

Acceptance of wind farms in remote locations, with no or few residents, is relatively understudied compared to acceptance of wind farms near residential areas or offshore wind farms. The aim of the paper is to study the acceptance of wind farms in the Austrian Alps by those who spend time in the Alps as part of their recreational activities, i.e., day trippers and tourists. This specific stakeholder group so far did not yet receive a lot of attention, as acceptance studies usually include a general public or the residents near concrete projects. In particular, this study aims to address the following research questions: (1) How well do visitors of the studied mountain areas accept the newly constructed wind farms? To distinguish between the locations of the wind farm, we also aim to compare acceptance levels of wind farms in the Alps with acceptance of farms in the agriculturally shaped lowlands and with acceptance of the technology in general. (2) Which factors predict acceptance and nonacceptance of the projects in the Alps, but also acceptance of wind farms in the lowlands and the technology in general? A quantitative survey was conducted to address these research questions.

The remainder of the paper is structured as follows: In the following section, we provide information on materials and methods, including background information on renewables and wind energy in Austria, details on data collection and methods for data analysis. In the result section, we report a descriptive analysis as well as the results from bivariate correlations and linear regressions. As respondents had the option to provide additional comments, we also briefly report a qualitative analysis of the provided comments. After a discussion of the results in the light of existing literature, we derive implications for policy makers. A short conclusion section completes the paper.

\section{Materials and methods}

\section{Case background: renewables and wind power in Austria}

In Austria, large proportions of the electricity generation come from renewable sources with hydropower accounting for approximately $60 \%$ of gross generation. For a further decarbonization of the electricity system, the shares of photovoltaics (PV, 1\%) and wind ( 9\%) need to increase and substitute the share of fossil fuels (22\% of gross generation, all numbers from (E-Control 2018, p. 28)). While rooftop PV is a feasible option on household (Fleiß et al. 2017) or farm-level scale (Brudermann et al. 2013), utility-level PV plants (solar farms) are basically non existent due to several challenges, such as land scarcity and competing land use. While medium-sized PV projects often are implemented as citizen power plants (Reinsberger et al. 2015), wind power projects are mainly implemented by the large power supply companies, and, apart from a few exceptions, ${ }^{1}$ without involvement of citizens or local communities.

Wind energy capacities have tripled between 2008 ( 1GW capacity) and 2018 ( $~ 3 \mathrm{GW}$ capacity, 1313 plants), ${ }^{2}$ and the $3 \mathrm{GW}$ target outlined for 2020 has been reached already. Austrian energy policy aims at $100 \%$ renewables in electricity generation by the year 2030. Wind is expected to play an important role in achieving the target, but concrete generation numbers are not stated in the Austrian Climate and Energy Strategy. ${ }^{3}$ Höltinger et al. (2016) assume a maximum capacity of approximately 50GW in Austria in their most optimistic modeling scenario and a capacity of approximately $40 \mathrm{GW}$ in their medium scenario. Given the geographical properties of Austria, without access to sea and thus without the option of building offshore wind farms, and the small-scale settlement structure, two types of locations appear particularly suitable for larger-scale wind

\footnotetext{
${ }_{1}$ The Austrian Wind Energy Association lists a total of four citizen participation projects on their website, as of April 2019, see www. igwindkraft.at/?mdoc_id=1000197 (accessed April 25, 2019).

2 Numbers from www.igwindkraft.at/fakten/ (accessed January 15, 2019).

${ }^{3}$ See mission2030.info/(accessed April 25, 2019).
} 
Fig. 1 Location of wind farms targeted in the survey $(\mathrm{T}=\mathrm{Tau}-$ ernwindpark, $\mathrm{S}=$ Steinriegel, $\mathrm{P}=$ Pretul, $\mathrm{F}=$ Freiländeralm; all parks are located in the federal state of Styria). A detailed map of wind power plant sites in Austria is provided by the Austrian Wind Energy Association. URL: www.igwindkraft.at/ landkarte/ (accessed April 25, 2019, in German)

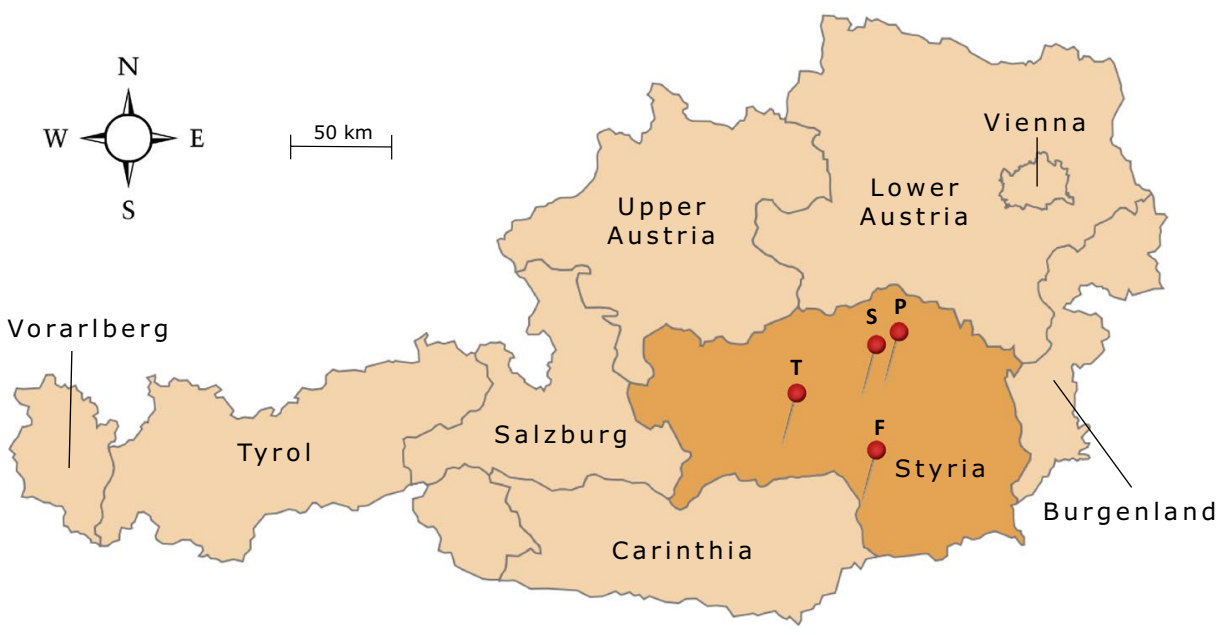

Table 1 Sample demographics and background

\begin{tabular}{|c|c|c|c|c|c|c|c|}
\hline \multicolumn{2}{|c|}{ Gender $(n=134)$} & \multicolumn{2}{|c|}{ Age $(n=132)$} & \multicolumn{2}{|c|}{ Education level $(n=135)$} & \multicolumn{2}{|c|}{ Frequency of visit $(n=120)$} \\
\hline Male & $83(62 \%)$ & Mean & 48.5 & University & $24(18 \%)$ & Several times per month & $12(10 \%)$ \\
\hline \multirow[t]{3}{*}{ Female } & $51(38 \%)$ & Median & 48.5 & High School & $37(27 \%)$ & Once in a month & $8(6 \%)$ \\
\hline & & SD & 16.0 & Technical college & $61(45 \%)$ & Several times per year & $33(28 \%)$ \\
\hline & & & & Compulsory school & $13(10 \%)$ & $1-2$ times per year & $67(56 \%)$ \\
\hline \multicolumn{4}{|c|}{ Driving distance to residence $(n=133)$} & \multicolumn{4}{|c|}{ Purpose of visit ( $n=137$, multiple answers possible) } \\
\hline \multicolumn{2}{|c|}{$>90 \min$} & $40(30 \%)$ & & Hiking & $97(71 \%)$ & & \\
\hline \multicolumn{2}{|c|}{ Within $61-90$ min } & $35(26 \%)$ & & Biking & $13(9 \%)$ & & \\
\hline \multicolumn{2}{|c|}{ Within $31-60 \mathrm{~min}$} & $16(12 \%)$ & & Strolling & $20(15 \%)$ & & \\
\hline \multirow{2}{*}{\multicolumn{2}{|c|}{$<=30 \mathrm{~min}$}} & $42(32 \%)$ & & Running & $8(6 \%)$ & & \\
\hline & & & & Other & $30(22 \%)$ & & \\
\hline
\end{tabular}

farms: the flat (and windy) agricultural lowland regions in the north and east of the country and remote locations in the (windy) Austrian Alps. While concerns of residents and local communities can easily become an issue in the lowlands, mountaintops are only sparsely populated, if inhabited at all. However, alpine regions are on the one hand habitat of wildlife (various species of deer, birds and rodents), and on the other hand popular areas for recreational activities such as hiking, skiing or cycling, for both locals and tourists.

\section{Data collection and analysis}

We conducted a quantitative survey in proximity to four recently constructed wind farms in the Austrian Alps. The surveyed wind farms were Windpark Pretul (42 MW capacity), Windpark Freiländeralm (6 MW), Windpark Steinriegel (38 MW) and Tauernwindpark (25 MW). All of these wind farms are located on mountains in the federal state of Styria in the east of Austria (see Fig. 1). The area around these farms is publically accessible and frequented by hikers and other visitors (e.g., cyclists and joggers). Between May and August 2018 we distributed the self-administered questionnaires to visitors at or near those wind farms. Since the respondents of our study were passing-by visitors with assumable limited patience, we limited the questionnaire to 36 items presented on a double-sided printed page. After excluding incomplete questionnaires and questionnaires filled by respondents under the age of 16, a total of 137 questionnaires could be used for further analysis.

The first part of the questionnaire included socio-demographic information (age, gender and education) and other information (frequency and purpose of visit in the area and distance to residence). Table 1 describes the study sample: Men are overrepresented in the sample (62\%) and half of the respondents are aged over 48 years. In terms of education, most of the respondents $(45 \%)$ had vocational/technical schooling followed by high schooling (27\%) and university (18\%). About $34 \%$ of the respondents visit the wind farm 
location occasionally, i.e., once or twice in a month or a few times in a year. While only $10 \%$ come for frequent visits, a significant portion of the respondents $(56 \%)$ visit the specific locality only once or twice in a year, and less than half of the respondents (44\%) visited from within $1 \mathrm{~h}$ of driving distance. The respondents also stated what they like to do while visiting these areas, and hiking was the most popular activity by far (71\%). Activities like strolling and running in the Alps were less frequently mentioned.

The second part of the questionnaire included questions related to dependent and independent variables, as identified in the literature review. The items were formulated as statements; respondents were asked to agree or disagree to these statements on a 5 -level Likert scale $(5=$ total agreement, $1=$ total disagreement). For this study, we chose four dependent variables referring to the acceptance of the wind farm at the respective site, of wind parks in the Alps and lower lands, and of wind parks as a generation technology in general. Independent variables consist of computed indices (six items) and individual constructs (four items). All computed indices have acceptable or good Cronbach's Alpha (CA); these are attitudes toward renewable energy $(\mathrm{CA}=.75)$, perceived degree of information $(\mathrm{CA}=.82)$, perceived benefits and reliability $(\mathrm{CA}=.77)$, annoyance toward wind generation technology $(\mathrm{CA}=.89)$, concern for environmental impacts $(\mathrm{CA}=.82)$ and trust in decision makers $(\mathrm{CA}=.94)$. Details on the applied instruments are provided in Supplement A. We then conducted a bivariate correlation analysis and a multiple linear regression to assess the relationships between dependent variables (acceptance levels for wind farms) and independent variables. In addition, the questionnaire included space for an optional short comment by the respondents; 18 of the 137 respondents (13\%) used this option.

\section{Limitations}

As any social science study, the present study is subject to limitations. Most importantly, the sampling strategy resulted in a convenience sample: data were collected on selected days at four different sites, where a large majority of approached visitors agreed to participate in the study. Since we collected the data in spring and summer, we missed out winter tourists. However, downhill skiing as the most prominent tourism activity in the Austrian Alps is anyway linked to the existence of technical infrastructure in the mountains, especially the lift system for the winter sports area, such as drag lifts, chair lifts or gondola lifts. It can be assumed that these tourists pay less attention to the nature next to the ski slope. Only ski tourers might be comparably sensitive to changes of the natural landscape as summer tourists. Therefore, full representativity cannot be assumed. However, an acceptance study with a representative Austrian sample has been already done by Sposato and Hampl (2018); the present study instead focuses on acceptance of wind parks in the Alps by visitors of the Alps and investigates factors that influence acceptance levels in this stakeholder group.

Another concern could be the sample size $(n=137)$. However, the assumption of normal distribution is relaxed when the sample size is exceeding 50 observations (Elliott and Woodward 2007, p. 25). Besides, the sample size tends to be adequate in order to run multiple regression analysis satisfying the minimum requirement of ten observations for each independent variable (Verma 2013, p. 147). We visually inspected the $Q-Q$ plot to check for normal distribution. Moreover, the assumption of multicollinearity was checked based on the collinearity diagnostics (variance inflation factor, VIF < 10; tolerance $>.2$ ) and variance proportion of regression coefficients (Field 2009, pp. 241-242, 297-299).

\section{Results}

This section presents the findings of the study. An overview of the descriptive statistics of response variables (mean, median of grouped data and standard deviation, SD) is presented in Table 2 . Table 3 presents paired mean comparisons of dependent variables (acceptance levels), and Table 4 shows a relationship matrix between dependent and independent variables. Finally, the regression models in Tables 5 and 6 explain the predicted variations in the hypothesized relationship between dependent and independent variables.

\section{Descriptive analysis}

In overall, acceptance for wind energy is fairly high in the sample. Wind farms as electricity generation technology are widely accepted with a mean acceptance level of 4.57 on the 5-level scale, and only low response variation $(\mathrm{SD}=.87)$. Acceptance for the concrete wind farm in the locality of the survey is also good (mean $=4.04, \mathrm{SD}=1.31)$, but slightly lower than for wind farms in the distant lowland areas (mean $=4.26, \mathrm{SD}=1.04)$. Interestingly, wind farms in the Alps in general are receiving lower acceptance levels (mean $=3.82, \mathrm{SD}=1.33$ ) than the concrete project in the (Alps) locality.

Attitude toward renewable energies is very high in the sample $($ mean $=4.46, \mathrm{SD}=.73)$; at the same time, respondents are concerned about climate change and its impacts (mean $=4.22, \mathrm{SD}=.96)$.

High agreement can also be found with regards to perceived benefits and reliability of wind technology (mean $=4.05, \mathrm{SD}=.86$ ). This is consistent with the low level of skepticism toward wind energy $($ mean $=2.23, \mathrm{SD}=1.17)$ and with the little concerns regarding environmental impacts, e.g., on animal wildlife and the natural environment 
Table 2 Descriptive statistics of dependent and independent variables
Table 3 Comparison of different acceptance levels

\begin{tabular}{llcl}
\hline Response variables & Mean & SD & Median $^{\mathrm{a}}$ \\
\hline Dependent variables & & & \\
Acceptance for wind farms in the locality & 4.04 & 1.31 & 4.38 \\
Acceptance for wind farms in the Alps region & 3.80 & 1.33 & 4.11 \\
Acceptance for wind farms in the lowland areas & 4.26 & 1.04 & 4.46 \\
Acceptance for wind farms as generation technology & 4.57 & .87 & 4.72 \\
Independent variables & & & \\
Attitude toward renewable energies & 4.46 & .73 & 4.71 \\
Perceived degree of information & 3.70 & .92 & 3.71 \\
Perceived benefits and reliability & 4.05 & .86 & 4.22 \\
Degree of trusts in decision makers & 3.25 & 1.27 & 3.19 \\
Concern for climate change & 4.22 & .96 & 4.37 \\
Belief in fossil fuel dependency & 3.64 & 1.25 & 3.81 \\
Skepticism toward wind energy & 2.23 & 1.17 & 2.09 \\
Annoyance toward wind energy and technology & 2.69 & 1.16 & 2.56 \\
Concerns for environmental impacts & 2.39 & 1.19 & 2.27 \\
Concerns regarding infrastructure & 2.34 & 1.36 & 2.02 \\
\hline
\end{tabular}

${ }^{\mathrm{a}}$ Median of grouped data

\begin{tabular}{lclccc}
\hline Pair-wise comparisons & Mean & $\begin{array}{l}\text { Std. Error } \\
\text { mean }\end{array}$ & T-statistic & Df & Sig. (one-tailed) \\
\hline Locality-Alps & .23 & .07 & 3.50 & 135 & $p<.001$ \\
Locality-Lowlands & -.23 & .09 & -2.54 & 134 & $p<.001$ \\
Locality-Technology & -.54 & .08 & -6.58 & 135 & $p<.001$ \\
Alps-Lowlands & -.45 & .09 & -4.81 & 134 & $p<.001$ \\
Alps-Technology & -.78 & .09 & -8.86 & 134 & $p<.001$ \\
Lowlands-Technology & -.31 & .07 & -4.60 & 133 & $p<.001$ \\
\hline
\end{tabular}

$($ mean $=2.39, \mathrm{SD}=1.19)$. Annoyance levels (visual impact, noise due to wind farms, etc.) are also rather low in the sample $($ mean $=2.67, \mathrm{SD}=1.17)$.

Due to the different levels of agreement for wind farms in different locations, and wind energy in general, paired t tests were conducted to analyze the differences for significance. As Table 3 shows, significant differences $(p<.001)$ exist among all paired comparisons. The respondents, on average, expressed higher acceptance for wind technology in general, for example, in comparison to wind farms in Alps areas $($ mean $=-.78, \mathrm{SE}=.09 ; t(134)=-8.86)$ with large effect size $(r=.61)$. Technology acceptance is also relatively higher than acceptance for wind farms in the locality $($ mean $=-.54, \mathrm{SE}=.08 ; t(137)=-6.58)$ with medium effect size $(r=.49)$. In the sample, acceptance levels follow a distinct order with acceptance for wind technology in general $>$ wind farms in lowland $>$ wind farms in locality $>$ wind farms in the Alps. To test whether acceptance levels differ between the four educational categories (University, High School, Technical College, Compulsory School), we applied Kruskal-Wallis $(H)$ tests. The test statistics suggest that there is no significant difference regarding acceptance levels between respondents with different educational backgrounds.

\section{Bivariate correlations}

We analyzed bivariate correlations for four different acceptance levels and the hypothesized independent variables (Table 4) and found (highly) significant relations at $p<.001$ and $p<.05$. Strong correlations (i.e., $r>.5$ or $r<-.5$ ) with high significance are highlighted with bold letters in the table.

Acceptance for wind farms in the locality shows a strong positive correlation with perceived benefits and reliability $(r=.67)$, a strong negative correlation with annoyance $(r=-.69)$ and a moderately strong negative correlation with environmental concern $(r=-.51)$. These correlations are highly significant at $p<.001$. The results are similar for the other dependent variables; the same three independent variables exhibit strongest correlations. Particularly strong and highly significant is the correlation between acceptance for 


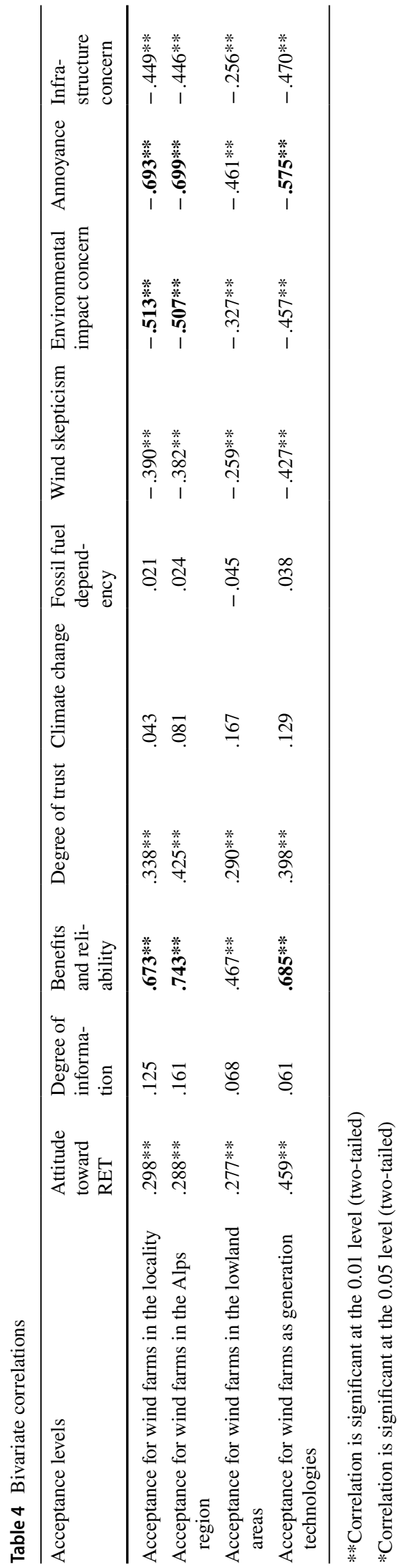

wind farms in the Alps and perceived benefits and reliability $(r=.74)$, as well as annoyance $(r=-.70)$. Acceptance for wind farms in general also strongly correlates with perceived benefits and reliability $(r=.69)$ and negatively with annoyance $(r=-.58)$. In addition, acceptance for wind farms in lowlands is moderately correlated with these variables, and the correlation is highly significant.

Attitudes toward renewable energy technologies, degree of trust in decision makers, and concerns regarding the necessary infrastructure do correlate with the acceptance variables; these correlations are weak or moderate, but highly significant. The variables perceived degree of information, climate change concern and beliefs in fossil fuel dependency do not correlate with the acceptance variables.

\section{Linear regressions}

After examining the bivariate correlation, we investigated the relationship between potential predictor variables and acceptance levels using multiple linear regression models. Table 5 shows the results of the regression analysis with the different acceptance levels as dependent variables and potential predictors as independent variables.

Model parameters of the four regression models are presented in Table 5. The adjusted $R^{2}$ tells how much of the variance in the acceptance variables can be explained by the predicted variables; the $F$-statistic shows significant fit of the models, that is, how much variability the models can explain in comparison to how much they cannot explain. Models 1, 2 and 4 exhibit relatively good proportions and significance levels, while model 3 has lower $\mathrm{R}^{2}$ and $\mathrm{F}$ values (see Table 5). Note that the assumption of independent errors in regression is met for all models. The values of DurbinWatson statistics are close to 2 for Model 1, 3 and 4, and is lower than 3 for Model 2 (see Table 5).

Standard Beta represents the strength of the relationship between predictor variables and the dependent variable; regression coefficients for all models are presented in Table 6. Model 1 and 2 (acceptance for the wind farm in the locality and wind farms in the Alps) show the same highly significant $(p<.001)$ predictor variables for the acceptance variables, namely perceived benefits and reliability (Std. Beta $=.34$ and .45 , respectively) and annoyance (Std. Beta $=-.40$ and -.30 , respectively). Model 3 (acceptance for wind farms in the lowlands) follows a similar trend, but at $p<.05$. Model 4 (technology acceptance) includes three significant, but slightly different predictors at $p<.001$ and $p<.05$ : attitudes toward renewable energy $($ Std. Beta $=.19)$, perceived benefits and reliability (Std. Beta $=.45)$ and wind skepticism (Std. Beta $=-.19$ ). It is worthy to note that no other predictor variables, except these four, can explain the acceptance levels. Thus, it can be stated that acceptance for wind farms in different locations and wind technology 
Table 5 Multiple linear regressions

\begin{tabular}{lllll}
\hline Model summary & $\begin{array}{l}\text { Regression model 1 } \\
\text { Acceptance for wind farms } \\
\text { in the locality }\end{array}$ & $\begin{array}{l}\text { Regression model 2 } \\
\text { Acceptance for wind farms in } \\
\text { the Alps region }\end{array}$ & $\begin{array}{l}\text { Regression model 3 } \\
\text { Acceptance for wind farms } \\
\text { in the lowland }\end{array}$ & $\begin{array}{l}\text { Regression model 4 } \\
\text { Acceptance for wind farms } \\
\text { as generation technology }\end{array}$ \\
\hline Adjusted R square & 0.62 & 0.63 & 0.31 & 0.56 \\
F-statistic & $18.40(p<.001)$ & $18.85(p<.001)$ & $5.79(p<.001)$ & $14.32(p<.001)$ \\
Durbin-Watson & 1.69 & 2.07 & 1.78 & 1.94 \\
df & 10 & 10 & 10 & 10 \\
$\mathrm{n}$ & 107 & 107 & 106 & 107 \\
\hline
\end{tabular}

increases with more positive perception of benefits and reliability, favorable attitudes toward renewable energy and lower level of skepticism and annoyance.

\section{Qualitative analysis of additional comments}

18 of the respondents chose to also add a short comment to the survey in the provided space on the questionnaire; five of these comments were explicitly positive toward wind energy and other renewables (e.g., by outlining benefits and comparing wind energy to nuclear energy); five comments were mixed (e.g., that the turbines are impressive, but there are too many; that the turbines do not fit to the landscape, and that hydropower is the better option). Only one of the comments was skeptical about wind power and stated that wind is the worst of renewable energies due to environmental and wildlife impact. The other seven comments included feedback to the questionnaire, background information about the respondents or constructive suggestions, e.g., that information posts with information on wind energy and the project would be interesting.

\section{Discussion}

We found rather high acceptance of wind farms among visitors in the locality of recently constructed wind farms in four Austrian alpine regions; concerns and skepticism about the technology and projects are on a quite low level. These observations are in line with the widely reported high acceptance for wind farms (e.g. Firestone et al. 2015). As in other studies, we also see that acceptance for the generation technology in general is higher than acceptance for concrete projects (Bell et al. 2005), and that projects "somewhere else" (i.e., in the Austrian lowlands) are better accepted than the project "here" (in the mountain location). With greater distance to a project, acceptance grows. One interesting and surprising outlier here is that the lowest acceptance is stated for "wind farms like this one in the Alps in general"; the concrete project thus receives higher acceptance than the abstract one in another alpine region-which is different from the observation made by Guo et al. (2015), where projects in the same county/city received higher acceptance than a project in closer proximity, or projects further away. One possible explanation is that the respondents in the present study compared the existing project to a potential project in an untouched mountain landscape and found the existing one more acceptable; this is in line with previous observations that existing projects are better accepted than planned projects: The practical inability to change the situation makes it more acceptable - a phenomenon well-known in psychology under the status quo bias in decision making (Samuelson and Zeckhauser 1988), and also observed in a related study on wind farms in Iceland (Sæpórsdóttir et al. 2018). Another reason could be that respondents, when answering this question, simply pictured a "more beautiful mountain than this one" which should not be spoiled, or viewed alpine environments as "sacred," but not the concrete site.

The main predictor for acceptance is the perceived benefits of the project, while annoyance level is the main predictor for non-acceptance. The conclusions of Rand and Hoen (2017) in their review for studies from North America thus also hold for the sample of visitors in the Austrian Alps. Concern regarding environmental impacts is mainly relevant for projects in the Alps, but less relevant for projects in the lowlands, or the technology in general. Alpine environments obviously matter to their visitors, and those who are concerned about impact stemming from such projects tend to be less welcoming to them. Other variables play a minor role, or no role at all in explaining acceptance or nonacceptance. For example, climate change concern is high in the sample, but not related to acceptance at all, and attitudes toward renewables only predict acceptance for the technology, but not acceptance for projects in the mountains or in the lowlands.

While non-acceptance of wind projects seems not to be a problematic issue in the selected Austrian mountain areas, opposition still might be met at some point, e.g., with an increase in numbers and density of projects. The clustering and number of turbines might cumulate and lead to opposition like reported in other studies (Petrova 2013; Walker et al. 2014); Frantal et al. (2017) on the other hand report 


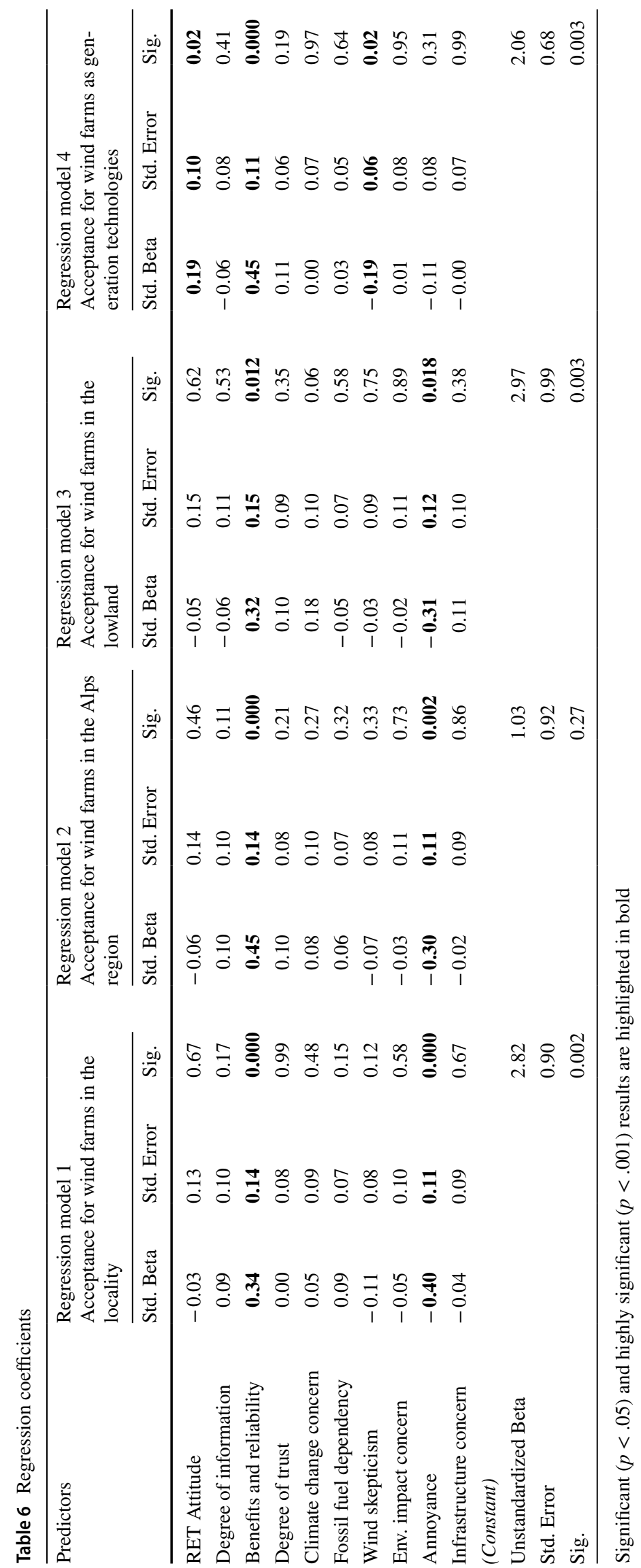


that the number of turbines and distance to them did not influence perceived landscape disruption, and in further consequence acceptance by residents; a similar observation was made by Kontogianni et al. (2014) in a Greek study. The target population of these studies, i.e., residents or a general public, however, differed from the target group in the current study.

The study reported in this paper was merely quantitative, and only a small share of respondents used the option to provide additional comments. Qualitative studies might help to add additional insights and relevant factors. In the literature, qualitative studies differ from quantitative studies with regards to which factors are considered most important for wind farm acceptance. For example, Spiess et al. (2015) found questions of aesthetics, technical performance and economic feasibility as crucial for acceptance in Swiss focus group discussions. Hall et al. (2013) found trust, distributional justice, procedural justice and place attachment as the common themes in qualitative interviews on seven Australian case studies. Apart from one respondent in our study who suggested to apply paintings on the rotors of the turbines, aesthetics was not mentioned in the additional comments. Topics like distributional justice did not pop-up in this study, and trust in decision makers on different political levels and trust in decisions made by energy company were found to be high regarding the wind energy topic. Besides, even if respondents report negative or positive attitude, these do not necessarily lead to intentions to act against a project. Cognitive and behavioral aspects of acceptance need to be distinguished (Walter 2014). In any case, upcoming projects in mountain areas seem not to expect significant opposition, at least not from the group of people who visit mountain areas for recreational purposes.

\section{Policy implications}

At the moment, no major resistance to wind power can be identified; this is true for the sample of mountain visitors used in this study, but also for the general population sample in Sposato and Hampl (2018). Policy makers therefore should focus on maintaining the positive image of the technology and on communicating the benefits and reliability of wind farms, as respective perceptions are a main predictor for acceptance. Operators on the other hand should take annoyance concerns seriously, as this factor is a main predictor for non-acceptance.

To maintain acceptance levels on a high level and to avoid large-scale opposition, several strategies could be applied. Thøgersen and Noblet (2012) e.g., found that everyday "green" behavior to a significant degree predicts acceptance of wind power; thus, promoting everyday green behaviors could prepare the grounds for increasing acceptance of more far-reaching sustainability policies, such as an expansion of wind power. Also, perceived fairness matters when it comes to acceptance, as reported, e.g., by Firestone et al. (2012) for offshore wind projects. If the population feels that costs and benefits are unevenly distributed-e.g., high profits for operators (and such wind farms are highly profitable), and at the same time increased eco-electricity taxes for end usersopposition might arise. Compensation efforts for the impact imposed on ecosystems or communities (García et al. 2016) might also be considered; this could span from financial compensation for affected communities or compensation activities (e.g., renaturation of other areas). Finally, integrating acceptance-relevant factors already into the planning phase (Zaunbrecher and Ziefle 2016) can mitigate opposition and negative press during the construction phase. Despite the currently high acceptance, such endeavors will facilitate the further expansion of wind power in efforts to decarbonize the electricity system.

Concerning further expansion of wind farm projects in alpine regions, special attention needs to be paid to potential trade-offs between these projects and tourism. Particularly, in regions with high degrees of naturalness, tourists might perceive wind power plants as significant impairment of landscape appearance. The results of this study indicate that summer tourists in the Austrian Alps have a positive attitude against wind power plants, although they primarily come for hiking and strolling the mountains, which are activities that are usually associated with the expectation of being able to enjoy a quiet and unspoiled landscape. In individual cases, it might even be possible to market the wind turbines as a special attraction for tourists. Energy tourism as a new niche of industrial tourism might even be a strategic tool to rebrand the image and to strengthen the competitive potential of the region (Frantál and Urbánková 2017). However, high acceptance should not be taken for granted, especially with an increasing number and size of wind turbines on the mountain ridges that are clearly visible even from a very great distance (Broekel and Alfken 2015). Moreover, one needs to be aware of the fact that the construction of wind power plants in the mountains always requires access to the construction site with large trucks in order to transport the turbines and other components. In many cases, this requires the construction of new roads and freight routes in mountainous terrain. The same is true for electricity transmission lines, since it might be necessary to build completely new transmission lines in previously largely untouched nature or to expand existing lines in order to connect the wind power plant to the electricity grid. Hence, it may well be that the wind turbines themselves are accepted, but that tourists find this additional infrastructure very disruptive. In this regard, Stefánsson et al. (2017) found in their analysis of the development of renewable energy projects in Iceland that tourists consider transmission lines in the Highlands as one of 
the least desirable infrastructures. In this way, renewable and sustainable energy generation with wind turbines in mountainous regions may well clash with the interests of the regional tourism industry.

Policies for extensive wind power generation in mountainous areas, thus, need to take interests of different stakeholder groups into consideration in order to be able to balance opportunities of sustainable energy production and potential conflicts with other forms of land use. The multiple use of resources in a close geographic proximity as it is the case with wind turbines in the Austrian Alps needs a smart allocation of different forms of land use in order to allow overall sustainable development. Here, the problem arises to assess the external effects of wind power plants already before they are actually built. Wind turbines impact alpine ecosystems, and therefore, regions with existing infrastructure (e.g., skiing areas) might be preferred over untouched landscapes when selecting sites for such projects. In comparison to many other forms of electricity generation, wind energy generation, however, has relatively minor environmental externalities. Such externalities are usually assessed according to standardized methods like life-cycle assessment within environmental impact assessment studies. In contrast, the main externalities of wind power plants are impacts on landscapes' visual aesthetic values, which strongly depend on the perception of the relevant groups of persons, such as residents or tourists, and thus, are much more difficult to assess a priori, i.e., before the plant is constructed. One promising solution to overcome the status quo bias also observed in this study might be the application of virtual technology in order to gather more consistent and accurate information on the factors that influence the acceptance of future wind power plants by residents, tourists and other stakeholders. Teisl et al. (2018) showed that tourists applying virtual reality tools were better at evaluating the impact of potential wind power projects and at forecasting potential behavioral reactions. Based on solid information about the perception of the impact of wind power plants, decision makers and planners can further develop wind power projects that take sufficient account of the interests of various interest groups. When geographical information is properly disseminated, public participation in the planning process can be improved (Díaz-Cuevas and DomínguezBravo 2015). In this way, land use conflicts can be avoided beforehand, and thus, high acceptance of the so urgently needed decarbonization of the energy system ensured.

\section{Conclusions}

This study focused on acceptance of wind energy projects in Austrian mountains, from the perspective of those who use these areas as (nearby) recreational areas. We found that the existing projects are well accepted, and that wind energy is a highly accepted technology in general. There is lower, but still sufficient acceptance for potential future projects in the Alps and a preference for projects in agricultural lowlands. This particular preference, however, might not be shared by residents in the lowlands.

The challenge for policy makers and operators of wind parks will be to maintain the high acceptance levels while scaling up the technology. Given that acceptance of wind power is higher in regions with a high density of wind turbines compared to regions with few turbines indicates good prospects for this endeavor. Nonetheless, factors such as annoyance, concerns regarding negative impacts and distributional fairness should be taken into account to not risk a tipping of public opinion. Providing possibilities for citizens and communities to participate in the planning and possibly also the operation of respective projects (e.g., by organizing them as citizen power plants) could further facilitate acceptance of and support for wind, and thus facilitate the transition to low-carbon electricity systems.

Acknowledgements Open access funding provided by University of Graz. We would like to thank Lukas Pertl, Anita Schwarhofer, Magdalena Rusch and the participants of the course Research Project Sustainability Management, held at University of Graz in the summer term 2018, for their support in collecting the data in harsh mountain environments with instable weather and signpost-free roads. Melanie Harrer is thanked for her assistance in data preparation and analysis.

\section{Compliance with ethical standards}

Conflict of interest The authors declare no conflict of interest.

Ethical standards The study was conducted in line with data protection regulations and under consideration of the official statement of the Ethics Committee at the University of Graz (https://www.uni-graz.at/ en/researching/organisation-plan/ethics-committee/).

Informed consent All data were collected on a voluntary and anonymous basis with informed consent, and data were treated confidentially; the study did not compromise physical or psychological integrity of respondents and did not touch their right for privacy or other important rights and interests (as specified in $\$ 3$ (2) of the statute of the Ethics Committee).

Open Access This article is distributed under the terms of the Creative Commons Attribution 4.0 International License (http://creativeco mmons.org/licenses/by/4.0/), which permits unrestricted use, distribution, and reproduction in any medium, provided you give appropriate credit to the original author(s) and the source, provide a link to the Creative Commons license, and indicate if changes were made. 


\section{References}

Bell D, Gray T, Haggett C (2005) The "social gap" in wind farm siting decisions: explanations and policy responses. Environ Politics 14(4):460-477. https://doi.org/10.1080/09644010500175833

Betakova V, Vojar J, Sklenicka P (2016) How education orientation affects attitudes toward wind energy and wind farms: implications for the planning process. Energy Sustain Soc 6(1):31. https://doi. org/10.1186/s13705-016-0096-6

Broekel T, Alfken C (2015) Gone with the wind? The impact of wind turbines on tourism demand. Energy Policy 86:506-519. https:// doi.org/10.1016/j.enpol.2015.08.005

Brudermann T, Reinsberger K, Orthofer A, Kislinger M, Posch A (2013) Photovoltaics in agriculture: a case study on decision making of farmers. Energy Policy 61:96-103. https://doi. org/10.1016/j.enpol.2013.06.081

D'Souza C, Yiridoe EK (2014) Social acceptance of wind energy development and planning in rural communities of Australia: a consumer analysis. Energy Policy 74(C):262-270. https://doi. org/10.1016/j.enpol.2014.08.035

de Sousa AJG, Kastenholz E (2015) Wind farms and the rural tourism experience-problem or possible productive integration? The views of visitors and residents of a Portuguese village. J Sustain Tour 23(8-9):1236-1256. https://doi.org/10.1080/09669 582.2015.1008499

Díaz-Cuevas P, Domínguez-Bravo J (2015) GIS, territory, and landscape in renewable energy management in Spain. In: Frolova M, Prados M-J, Nadaï A (eds) Renewable energies and European landscapes: lessons from Southern European cases. Springer, Dordrecht, pp 279-294. https://doi. org/10.1007/978-94-017-9843-3_15

Duić N (2015) Is the success of clean energy guaranteed? Clean Technol Environ Policy 17(8):2093-2100. https://doi.org/10.1007/ s10098-015-0969-y

E-Control (2018) Statistikbroschüre 2018-Unsere Energie in Zahlen betrachtet. Vienna. https://www.e-control.at/documents/20903 /388512/Statistikbroschuere_2018.pdf/7dee68bb-b2eb-16d59124-c5de5907a25d. Accessed 25 Apr 2019

Elliott A, Woodward W (2007) Statistical analysis quick reference guidebook. Sage, Thousand Oaks. https://doi.org/10.4135/97814 12985949

Fergen J, Jacquet JB (2016) Beauty in motion: expectations, attitudes, and values of wind energy development in the rural U.S. Energy Res Soc Sci 11:133-141. https://doi.org/10.1016/j.erss.2015.09.003

Field A (2009) Discovering statistics using IBM SPSS statistics, 3rd edn. Sage Publications, London

Firestone J, Kempton W, Lilley MB, Samoteskul K (2012) Public acceptance of offshore wind power: does perceived fairness of process matter? J Environ Plan Manage 55(10):1387-1402. https ://doi.org/10.1080/09640568.2012.688658

Firestone J, Bates A, Knapp LA (2015) See me, feel me, touch me, heal me: wind turbines, culture, landscapes, and sound impressions. Land Use Policy 46:241-249. https://doi.org/10.1016/j.landusepol .2015.02.015

Fleiß E, Hatzl S, Seebauer S, Posch A (2017) Money, not morale: the impact of desires and beliefs on private investment in photovoltaic citizen participation initiatives. J Clean Prod 141:920-927. https ://doi.org/10.1016/j.jclepro.2016.09.123

Fokaides PA, Miltiadous IC, Neophytou MKA, Spyridou LP (2014) Promotion of wind energy in isolated energy systems: the case of the Orites wind farm. Clean Technol Environ Policy 16(3):477488. https://doi.org/10.1007/s10098-013-0642-2

Frantál B, Kunc J (2011) Wind turbines in tourism landscapes: Czech Experience. Ann Tour Res 38(2):499-519. https://doi. org/10.1016/j.annals.2010.10.007
Frantál B, Urbánková R (2017) Energy tourism: an emerging field of study. Curr Issues Tour 20(13):1395-1412. https://doi. org/10.1080/13683500.2014.987734

Frantal B, Van der Horst D, Kunc J, Janurova M (2017) Landscape disruption or just a lack of economic benefits? Exploring factors behind the negative perceptions of wind turbines. Tájökológiai Lapok 15(2):139-147

García JH, Cherry TL, Kallbekken S, Torvanger A (2016) Willingness to accept local wind energy development: Does the compensation mechanism matter? Energy Policy 99:165-173. https ://doi.org/10.1016/j.enpol.2016.09.046

Groth TM, Vogt CA (2014) Rural wind farm development: social, environmental and economic features important to local residents. Renew Energy 63(January):1-8. https://doi.org/10.1016/j. renene.2013.08.035

Guo Y, Ru P, Su J, Anadon LD (2015) Not in my backyard, but not far away from me: local acceptance of wind power in China. Energy 82:722-733. https://doi.org/10.1016/j.energ y.2015.01.082

Hall N, Ashworth P, Devine-Wright P (2013) Societal acceptance of wind farms: analysis of four common themes across Australian case studies. Energy Policy 58:200-208. https://doi.org/10.1016/j. enpol.2013.03.009

Höltinger S, Salak B, Schauppenlehner T, Scherhaufer P, Schmidt J (2016) Austria's wind energy potential-a participatory modeling approach to assess socio-political and market acceptance. Energy Policy 98(2016):49-61. https://doi.org/10.1016/j.enpol .2016.08.010

IEA (2017) Report: World Energy Outlook 2017. Oil Gas European Magazine. OECD. https://doi.org/10.1787/weo-2017-en

Kontogianni A, Tourkolias C, Skourtos M, Damigos D (2014) Planning globally, protesting locally: patterns in community perceptions towards the installation of wind farms. Renew Energy 66:170 177. https://doi.org/10.1016/j.renene.2013.11.074

Liebe U, Bartczak A, Meyerhoff J (2017) A turbine is not only a turbine: the role of social context and fairness characteristics for the local acceptance of wind power. Energy Policy 107:300-308. https://doi.org/10.1016/j.enpol.2017.04.043

Liu D, Upchurch RS, Curtis C, Lusby C (2016) Chinese domestic tourist perceptions of wind farms experiences. J Sustain Tour 24(11):1569-1583. https://doi.org/10.1080/09669582.2016.11588 26

McKenna R, Ostman P, Fichtner W (2016) Key challenges and prospects for large wind turbines. Renew Sustain Energy Rev 53:1212-1221. https://doi.org/10.1016/j.rser.2015.09.080

Motosu M, Maruyama Y (2016) Local acceptance by people with unvoiced opinions living close to a wind farm: a case study from Japan. Energy Policy 91:362-370. https://doi.org/10.1016/j.enpol .2016 .01 .018

Petrova MA (2013) NIMBYism revisited: public acceptance of wind energy in the United States. Wiley Interdiscip Rev Clim Change 4(6):575-601. https://doi.org/10.1002/wcc.250

Rand J, Hoen B (2017) Thirty years of North American wind energy acceptance research: What have we learned? Energy Res Soc Sci 29:135-148. https://doi.org/10.1016/j.erss.2017.05.019

Reinsberger K, Brudermann T, Hatzl S, Fleiß E, Posch A (2015) Photovoltaic diffusion from the bottom-up: analytical investigation of critical factors. Appl Energy 159:178-187. https://doi. org/10.1016/j.apenergy.2015.08.117

Sæpórsdóttir AD, Ólafsdóttir R, Smith D (2018) Turbulent times: tourists' attitudes towards wind turbines in the Southern Highlands in Iceland. Int J Sustain Energy 37(9):886-901. https://doi. org/10.1080/14786451.2017.1388236

Samuelson W, Zeckhauser R (1988) Status quo bias in decision making. J Risk Uncertain 1(1):7-59. https://doi.org/10.1007/BF000 55564 
Scherhaufer P, Höltinger S, Salak B, Schauppenlehner T, Schmidt J (2017) Patterns of acceptance and non-acceptance within energy landscapes: a case study on wind energy expansion in Austria. Energy Policy 109:863-870. https://doi.org/10.1016/j.enpol .2017.05.057

Silva L, Delicado A (2017) Wind farms and rural tourism: a Portuguese case study of residents' and visitors' perceptions and attitudes. Morav Geogr Rep 25(4):248-256

Sonnberger M, Ruddat M (2017) Local and socio-political acceptance of wind farms in Germany. Technol Soc 51:56-65. https://doi. org/10.1016/j.techsoc.2017.07.005

Spiess H, Lobsiger-Kägi E, Carabias-Hütter V, Marcolla A (2015) Future acceptance of wind energy production: exploring future local acceptance of wind energy production in a Swiss alpine region. Technol Forecast Soc Change 101:263-274. https://doi. org/10.1016/j.techfore.2015.06.042

Sposato RG, Hampl N (2018) Worldviews as predictors of wind and solar energy support in Austria: bridging social acceptance and risk perception research. Energy Res Soc Sci 42:237-246. https ://doi.org/10.1016/j.erss.2018.03.012

Stefánsson P, Sæbórsdóttir AD, Hall CM (2017) When tourists meet transmission lines: the effects of electric transmission lines on tourism in Iceland. Energy Res Soc Sci 34:82-92. https://doi. org/10.1016/j.erss.2017.06.032

Tatchley C, Paton H, Robertson E, Minderman J, Hanley N, Park K (2016) Drivers of public attitudes towards small wind turbines in the UK. PLoS ONE 11(3):e0152033. https://doi.org/10.6084/ m9.figshare.3113413

Teisl MF, Noblet CL, Corey RR, Giudice NA (2018) Seeing clearly in a virtual reality: tourist reactions to an offshore wind project. Energy Policy 122:601-611. https://doi.org/10.1016/j.enpol .2018.08.018

Thøgersen J, Noblet C (2012) Does green consumerism increase the acceptance of wind power? Energy Policy 51:854-862. https:// doi.org/10.1016/j.enpol.2012.09.044

University of Klagenfurt, WU Vienna University of Economics and Business, Deloitte Austria, \& Wien Energie (2018) Erneuerbare Energien in Österreich. Der jährliche Stimmungsbarometer der österreichischen Bevölkerung zu erneuerbaren Energien [Renewable Energies in Austria_Annual Barometer of Public Opinion]. Vienna. https://www2.deloitte.com/content/dam/Deloitte/at/

\section{Affiliations}

\section{Thomas Brudermann ${ }^{1}\left(\mathbb{D} \cdot\right.$ Rafia Zaman ${ }^{1,2}\left(\mathbb{D} \cdot\right.$ Alfred Posch $^{1}$}

Thomas Brudermann

Thomas.Brudermann@uni-graz.at

1 Institute of Systems Sciences, Innovation and Sustainability Research, University of Graz, Merangasse 18/I, 8010 Graz, Austria
Documents/energy-resources/at-studie-erneuerbare-energie-2019. pdf

Verma JP (2013) Data analysis in management with SPSS software. Springer, New Delhi

Voltaire L, Loureiro ML, Knudsen C, Nunes PAL (2017) The impact of offshore wind farms on beach recreation demand: policy intake from an economic study on the Catalan coast. Mar Policy 81:116123. https://doi.org/10.1016/J.MARPOL.2017.03.019

Walker C, Baxter J, Ouellette D (2014) Beyond rhetoric to understanding determinants Of wind turbine support and conflict in two Ontario, Canada Communities. Environ Plan A 46(3):730-745. https://doi.org/10.1068/a130004p

Walter G (2014) Determining the local acceptance of wind energy projects in Switzerland: the importance of general attitudes and project characteristics. Energy Res Soc Sci 4(C):78-88. https:// doi.org/10.1016/j.erss.2014.09.003

Warren CR, McFadyen M (2010) Does community ownership affect public attitudes to wind energy? A case study from southwest Scotland. Land Use Policy 27(2):204-213. https://doi. org/10.1016/j.landusepol.2008.12.010

Westerberg V, Jacobsen JB, Lifran R (2013) The case for offshore wind farms, artificial reefs and sustainable tourism in the French mediterranean. Tour Manag 34:172-183. https://doi.org/10.1016/J. TOURMAN.2012.04.008

Westerberg V, Jacobsen JB, Lifran R (2015) Offshore wind farms in Southern Europe-determining tourist preference and social acceptance. Energy Res Soc Sci 10:165-179. https://doi. org/10.1016/J.ERSS.2015.07.005

Yuan X, Zuo J, Huisingh D (2015) Social acceptance of wind power: a case study of Shandong Province, China. J Clean Prod 92:168 178. https://doi.org/10.1016/j.jclepro.2014.12.097

Zaunbrecher BS, Ziefle M (2016) Integrating acceptance-relevant factors into wind power planning: a discussion. Sustain Cities Soc 27:307-314. https://doi.org/10.1016/j.scs.2016.08.018

Publisher's Note Springer Nature remains neutral with regard to jurisdictional claims in published maps and institutional affiliations.

2 Business Administration Discipline, Khulna University, Khulna 9208, Bangladesh 